\title{
Microstructure controls and their effects on the properties of $\mathrm{Bi}_{2} \mathrm{Sr}_{2} \mathrm{Ca}_{1} \mathrm{Cu}_{2} \mathrm{O}_{x}$ superconductors
}

\author{
K TOGANO ${ }^{1,2,3} *$, H KUMAKURA ${ }^{1,3}$, H KITAGUCHI $^{1,3}$, H FUJII ${ }^{1,3}$, H MIAO $^{3}$, Y HISHINUMA ${ }^{2}$, \\ Y NEMOTO ${ }^{2}$, M OKADA ${ }^{4}$, J SATO ${ }^{5}$ and T HASEGAWA ${ }^{6}$ \\ 'National Research Institute for Metals, 1-2-1 Sengen, Tsukuba, Ibaraki 305-0047, Japan \\ ${ }^{2}$ University of Tsukuba, Cooperative Graduate School, 1-1-1 Tennodai, Tsukuba 305-0006, Japan \\ ${ }^{3}$ CREST, Japan Science and Technology Corporation (JST), 2-1-6 Sengen, Tsukuba 305-0047, Japan \\ ${ }^{4}$ Hitachi Research Laboratory, Hitachi Ltd., Ohmika-cho 7-1-1, Hitachi Ibaraki 319-12, Japan \\ ${ }^{5}$ Hitachi Cable Ltd., Kidamari-cho 3550, Tsuchiura, Ibaraki 300-0026, Japan \\ ${ }^{6}$ Showa Electric Wire and Cable Co. Ltd., Odasakae 2-1-1, Kawasaki-ku, Kawasaki 210-0843, Japan
}

\begin{abstract}
This paper reports our recent progresses in the development of $\mathrm{Bi}_{2} \mathrm{Sr}_{2} \mathrm{Ca}_{1} \mathrm{Cu}_{2} \mathrm{O}_{x} / \mathrm{Ag}$ tape conductors for the applications of magnetic field generation in liquid helium or around $20 \mathrm{~K}$, using a refrigerator. We have carried out extensive work to optimize the processing parameters, investigating the relationship between the microstructure and transport $J_{c}$. We have found that the partial melting in oxygen atmosphere is effective to have large transport $J_{c}$ with good reproducibility. The pre-annealing and intermediate rolling (PAIR) process has been successfully applied to the multilayer conductors to improve the grain alignment and transport $J_{c^{*}}$. The $J_{c}$ of $5 \times 10^{5} \mathrm{~A} / \mathrm{cm}^{2}$ at $4.2 \mathrm{~K}$ and $10 \mathrm{~T}$ has been achieved, which is the highest value reported so far. Two magnets fabricated by using different types of $\mathrm{Bi}-2212 / \mathrm{Ag}$ conductors were tested. One is a magnet designed as an insert magnet for a $18 \mathrm{~T}$-class large bore $\mathrm{Nb}-\mathrm{Ti} / \mathrm{Nb}_{3} \mathrm{Sn}$ superconducting magnet. The conductor of this magnet was multifilamentary tape processed by powder-in-tube method. The $I_{\mathrm{c}}$ was $98 \mathrm{~A}$ in the backup field of $18 \mathrm{~T}$, which generated the self field of $1.79 \mathrm{~T}$. A large pancake coil was fabricated with multilayer conductor and tested under the operation of cryocooler system. The coil was stably operated up to the $J_{c}$ of the coil at the temperatures below $30 \mathrm{~K}$.
\end{abstract}

Keywords. $\mathrm{Bi}_{2} \mathrm{Sr}_{2} \mathrm{Ca}_{1} \mathrm{Cu}_{2} \mathrm{O}_{x}$ superconductor; grain alignment; critical current density; tape; magnet.

\section{Introduction}

Among the many high temperature superconductors, $\mathrm{Bi}_{2} \mathrm{Sr}_{2} \mathrm{Ca}_{1} \mathrm{Cu}_{2} \mathrm{O}_{x}(\mathrm{Bi}-2212)$ is one of the most promising materials for practical application because of its extremely high transport critical current density $\left(J_{c}\right)$ at low temperatures even in strong magnetic fields. In recent years, many investigations of magnet fabrication using $\mathrm{Bi}-2212$ superconducting tapes have been reported (Balachandran et al 1994; Shibutani et al 1994; Tenbrink and Krauth 1994; Tomita et al 1994, 1995; Okada et al 1996). Bi-2212/Ag tapes were prepared by applying a meltsolidification method, which produced an excellent microstructure of highly oriented Bi-2212 crystals (Kase et al 1991). Due to this preferable microstructure, they show excellent critical current density $\left(J_{c}\right)$ values higher than $10^{5} \mathrm{~A} / \mathrm{cm}^{2}$, even in magnetic fields above $25 \mathrm{~T}$ (Tesla) at $4.2 \mathrm{~K}$. In the previous work (Okada et al 1996), we fabricated small magnets composed of pancake type coils using $\mathrm{Bi}-2212 / \mathrm{Ag}$ multifilamentary tapes prepared by the powder-in-tube method and melt-solidification process. Those small magnets were tested at $4.2 \mathrm{~K}$ as the insert magnet of a Nb-Ti/ $/ \mathrm{Nb}_{3} \mathrm{Sn}$ superconducting magnet system and one of the magnet generated about $1.8 \mathrm{~T}$ in the

*Author for correspondence back-up field of $21 \mathrm{~T}$, so that the whole system achieved the highest magnetic field of $22.8 \mathrm{~T}$ generated only by superconducting state. Although the magnet had a small size $(13 \mathrm{~mm}$ inner dia., $49 \mathrm{~mm}$ outer dia. and $55 \mathrm{~mm}$ height), the result suggested that the combination of Bi-2212 and conventional metallic superconductor would be very promising to construct a high-field superconducting magnet system, such as a high-field NMR magnet.

Another interesting application of Bi-2212 is a magnet operated at elevated temperatures. For example, at $20 \mathrm{~K}$ where the efficiency of a Gifford-McMahon (GM) cryocooler becomes high enough, Bi-2212 also shows excellent $J_{\mathrm{c}}$ values. In general, $\mathrm{Bi}-2212 / \mathrm{Ag}$ tape conductors are more easily synthesized than $\mathrm{Bi}-2223 / \mathrm{Ag}$ conductors because of simpler fabrication procedure. These suggest that the $\mathrm{Bi}-2212$ is another candidate for' a conductor of a cryogen-free superconducting magnet operated with cryocooler.

In this paper, we report our recent progresses in the development of $\mathrm{Bi}_{2} \mathrm{Sr}_{2} \mathrm{Ca}_{1} \mathrm{Cu}_{2} \mathrm{O}_{x} / \mathrm{Ag}$ tape conductors for the applications of magnetic field generation in liquid helium or at below $20 \mathrm{~K}$ by using a refrigerator. We have carried out an extensive work to optimize the processing parameters to have large $J_{c}$ with good reproducibility, investigating the relationship between the microstructure and transport $J_{c^{\circ}}$. The paper also reports 
the results of coil tests in liquid helium and cryocooler operation.

\section{Fabrication of Bi-2212/Ag tape}

We are developing three processes to fabricate $\mathrm{Bi}$ 2212/Ag long tape and its coil, which are dip-coating, powder-in-tube (PIT), and lamination processes. Figure 1 shows the schematic diagram of these three processes. In the dip-coating process, $\mathrm{Ag}$ tape is continuously dipped into the slurry to be coated with the mixture of oxide and organic binders. The lamination process is the modification of the dip-coating process, in which several coated tapes are stacked and wrapped by $\mathrm{Ag}$ or Ag-alloy foil. The assembly is then cold rolled into a tape with multilayer structure.

In all these processes, the tape is given the heat treatment of partial melting and slow cooling in order to achieve good grain alignment of $\mathrm{Bi}-2212$. We found that the partial melting and slow solidification in pure oxygen atmosphere brings about a larger transport $J_{c}$ than in ambient atmosphere with good reproducibility as shown in figure 2 (Kumakura et al 1996). The investigation by high resolution transmission electron microscopy indicated that the partial melting and slow solidification in low oxygen partial pressure results in the formation of amorphous layer at the grain boundary, resulting in the weak coupling (Fujii et al 1997). Figure 3 shows the typical transport $J_{c}$ as functions of magnetic field and temperatures. The tapes have high transport $J_{c}$ which exceeds well over $105 \mathrm{~A} / \mathrm{cm}^{2}$ in applied magnetic fields at the temperatures below $30 \mathrm{~K}$.
Recently, we have developed the pre-annealing and intermediate rolling (PAIR) process in order to improve the gain alignment. Figure 4 shows the procedure of the PAIR process, which is particularly effective when applied for lamination process (Miao et al 1998a). Figure 5 shows the effect of pre-annealing (PA) and intermediate annealing (IR) on the transport $J_{c}$ of the Bi-2212/Ag multilayer tape processed by lamination process. These results indicate that the application of PAIR process to conventional partial melting process increases the $J_{c}$ to about 3 times. Very recently, we achieved critical current density of $5 \times 10^{5} \mathrm{~A} / \mathrm{cm}^{2}$ at $4.2 \mathrm{~K}$ and $10 \mathrm{~T}$ by optimizing the PAIR process and conductor fabrication procedure, which is the highest critical current density of the tape reported so far (Miao et al 1998b). This large increase of $J_{c}$ was caused by the large improvement of grain alignment of $\mathrm{Bi}-2212$ as shown in figure 6 .

\section{Coil test in liquid helium to generate high magnetic field}

Bi-2212/Ag multifilamentary tapes with 19 oxide cores, whose size was $0.15 \mathrm{~mm}$ in thickness, $5 \mathrm{~mm}$ in width and $50 \mathrm{~m}$ in length were prepared by the powder-in-tube method (Okada et al 1995). The tapes were then wound in a double pancake form, partially melted at around $880^{\circ} \mathrm{C}$ and then furnace cooled in a flowing pure oxygen atmosphere. Alumina paper was used as an insulator. Finally, the coils were annealed in the atmosphere of low oxygen partial pressure in order to optimize the carrier concentration. After the heat treatment, the coils were impregnated with an epoxy resin with low viscosity.

\section{Continuous Dip-coating}

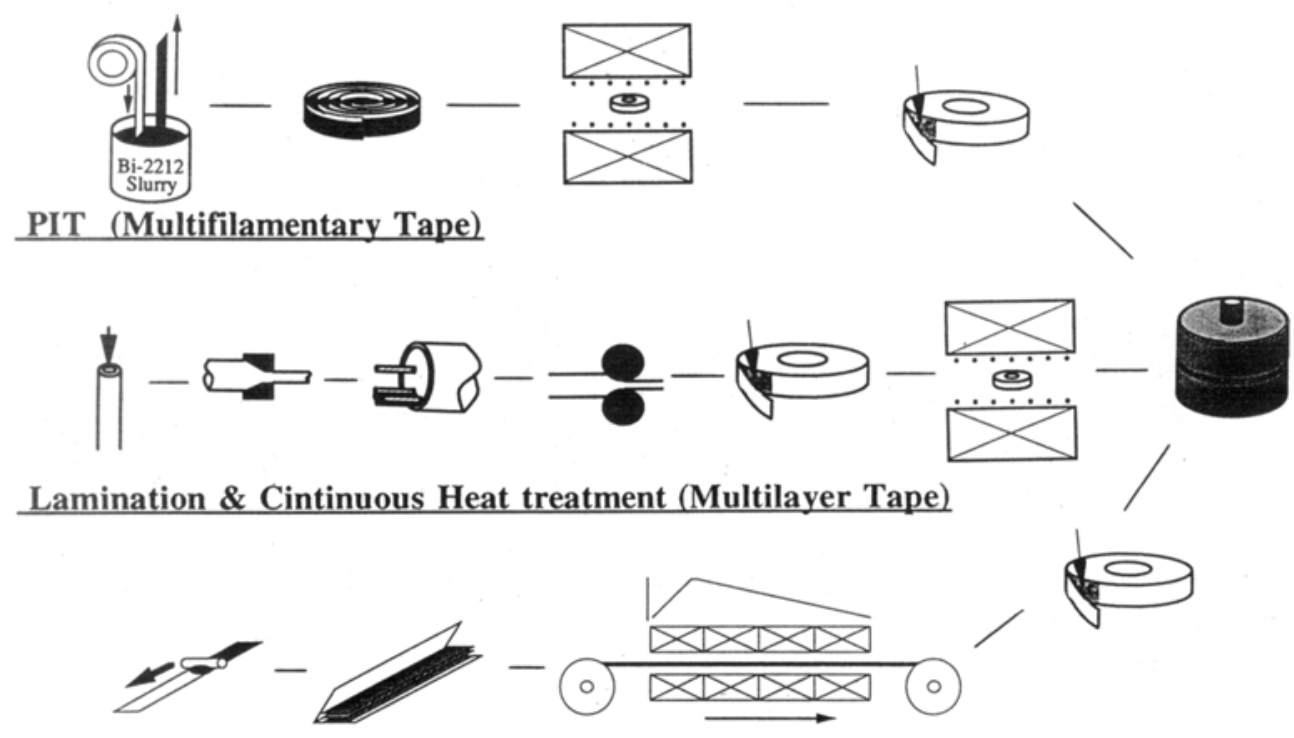

Figure 1. Schematic diagrams of three processes for the fabrication of long $\mathrm{Bi}-2212 / \mathrm{Ag}$ tape and coils. 
Then, ten double pancake coils were stacked to fabricate an insert magnet. Figure 7 shows the photograph of an insert magnet, which was $125 \mathrm{~mm}$ in height, $129 \mathrm{~mm}$ in outer diameter and had a clear bore of $25 \mathrm{~mm}$. The magnet was encased in a metal former and impregnated with epoxy resin for the support to strong electromagnetic force. Voltage terminals were soldered on the outermost

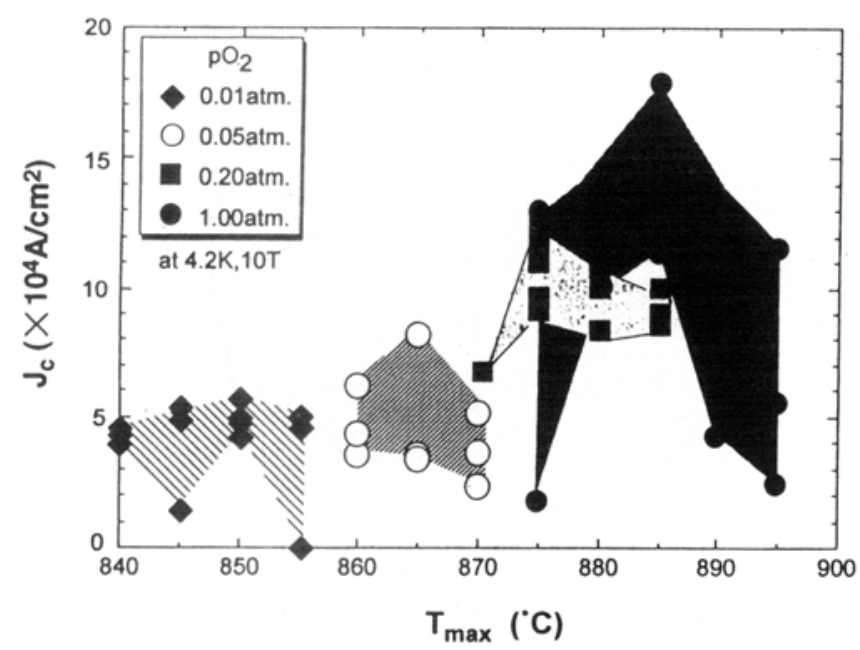

Figure 2. Critical current density $J_{\mathrm{c}}$ at $4.2 \mathrm{~K}$ and $10 \mathrm{~T}$ as a function of maximum temperature of the heat treatment schedule. The heat treatment of the partial melting and solidification was performed under several oxygen partial pressure.

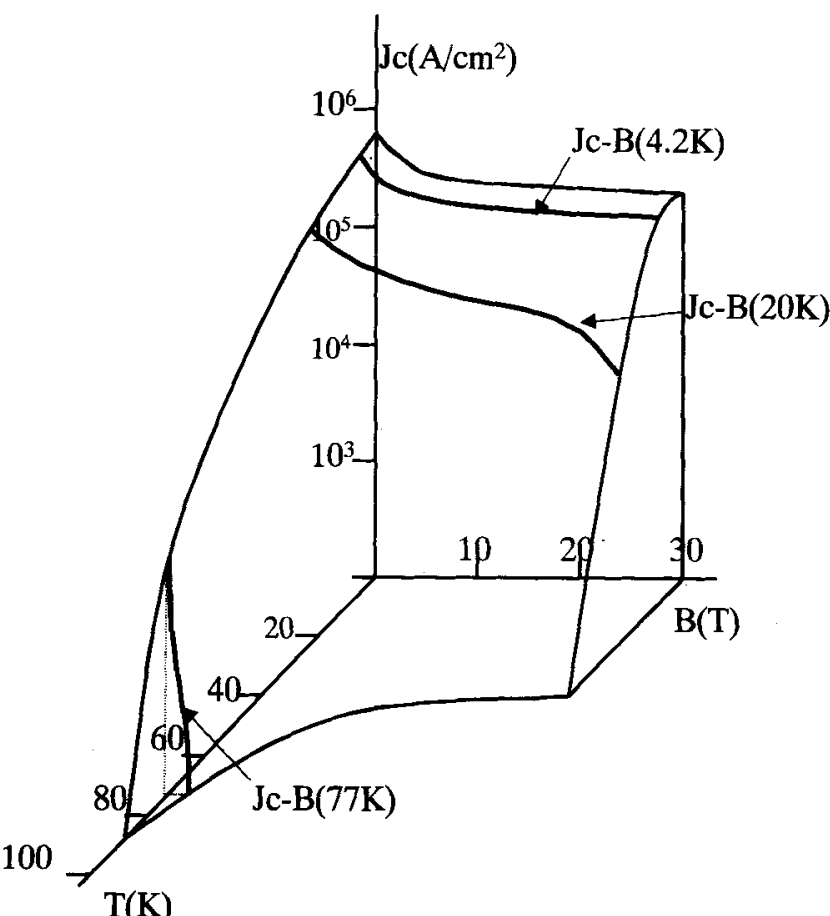

Figure 3. Typical transport $J_{c}$ of the Bi-2212/Ag superconducting tape as functions of applied magnetic field and temperature. The magnetic field is applied parallel to the tape surface. turn of each double pancake coil and also on the current leads. The critical current of $l_{\mathrm{c}}$ of the coil was defined by $10^{-13} \mathrm{ohm}-\mathrm{m}$ criterion. The critical current density of the coil $J_{\text {c-coil }}$, was calculated from $I_{\mathrm{c}}$ and the overall cross section of the conductor. The $J_{\mathrm{c}}$ of the $\mathrm{Bi}-2212$ oxide core, $J_{c-\text {-oxide }}$ was also calculated from $I_{c}$ and the cross sectional area of the oxide core. The generated magnetic field of the magnet was measured by using a Hall sensor. Backup magnetic fields up to $18 \mathrm{~T}$ were applied using a large bore $\mathrm{Nb}-\mathrm{Ti} / \mathrm{Nb}_{3} \mathrm{Sn}$ superconducting magnet at Tsukuba Magnet Laboratories of National Research Institute for Metals.

The $J_{c-\text {-oxide }}$ calculated from the $I_{c}$ defined by the $10^{-13} \mathrm{ohm}-\mathrm{m}$ criterion is plotted as a function of the centre magnetic field in figure 8 . In the backup field of $18 \mathrm{~T}$, the insert magnet showed $I_{\mathrm{c}}$ value of $98 \mathrm{~A}$,

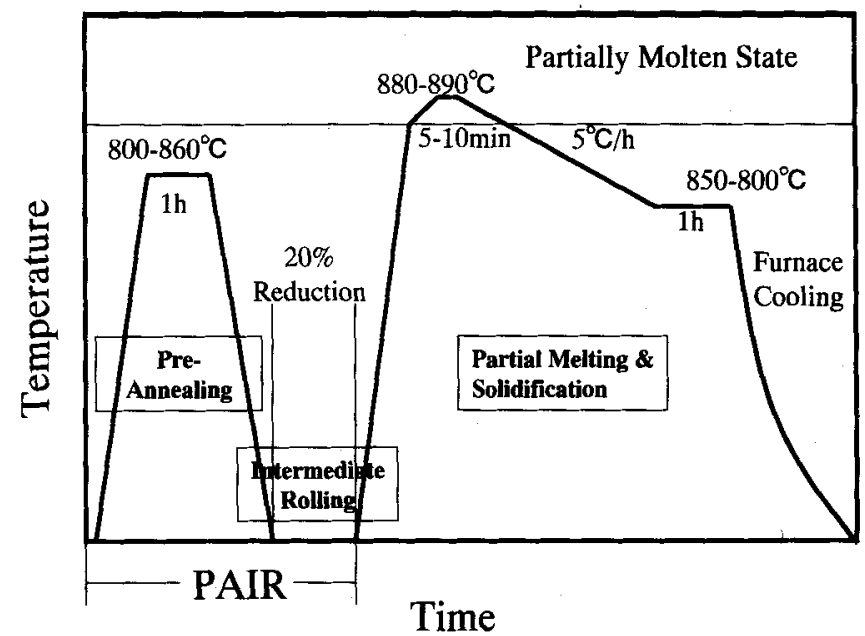

Figure 4. Procedure of the pre-annealing and intermediate rolling (PAIR) process.

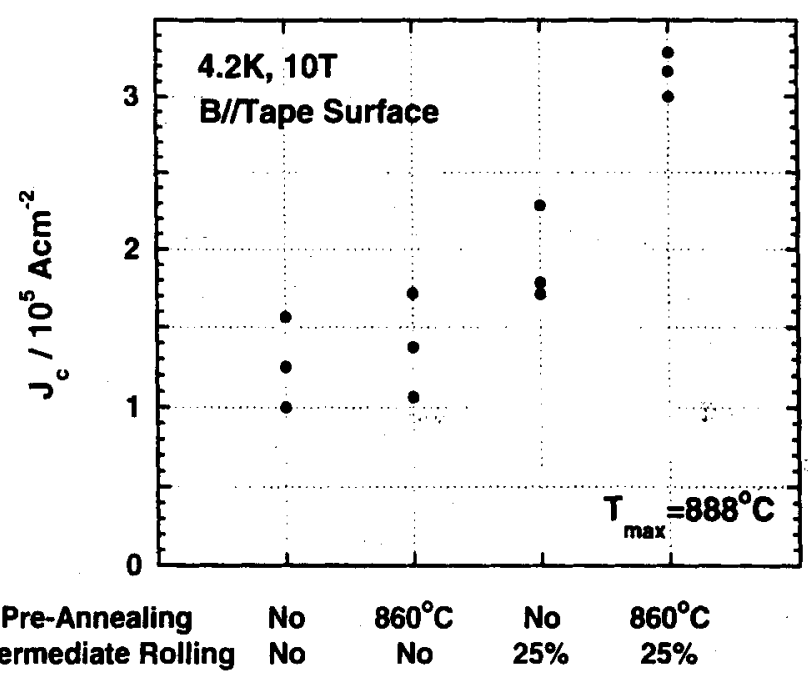

Figure 5. Effect of pre-annealing (PA) and intermediate rolling (IR) on $J_{c}$ of the $\mathrm{Bi}-2212 / \mathrm{Ag}$ multilayer tape. 
which corresponds to the $J_{c-x i d e}$ of about $3 \times 10^{4} \mathrm{~A} / \mathrm{cm}^{2}$ and the $J_{\text {c-coil }}$ of $3.6 \times 10^{3} \mathrm{~A} / \mathrm{cm}^{2}$. At this current, the self-field of the insert magnet was $1.79 \mathrm{~T}$, resulting in a total magnetic field of about $19.8 \mathrm{~T}$. The $J_{\text {c-coil }}$ is $1 / 3-1 / 4$ of that of the small coils which was reported in previous work (Okada et al 1996), and we are now improving the performance of the large magnets.

\section{Coil tests under cryocooler operation}

The Bi-2212 coil used for the cryocooler test was fabricated by a react and wind method using Bi-2212/Ag multilayer composite tapes prepared by the lamination process. Ag tapes of $20 \mu \mathrm{m}$ in thickness and $3 \mathrm{~mm}$ width were coated with slurry and those tapes were stacked together and wrapped with $25 \mu \mathrm{m}$ thick $\mathrm{Ag}-0.2 \% \mathrm{Mg}$ alloy tape. The mechanical strength of the tape was much enhanced by using this $\mathrm{Ag}-0.2 \% \mathrm{Mg}$ alloy. This multilayer tape was continuously heat treated by travelling the tape through a long pipe furnace having a precise temperature gradient. This heat treatment gave a partial
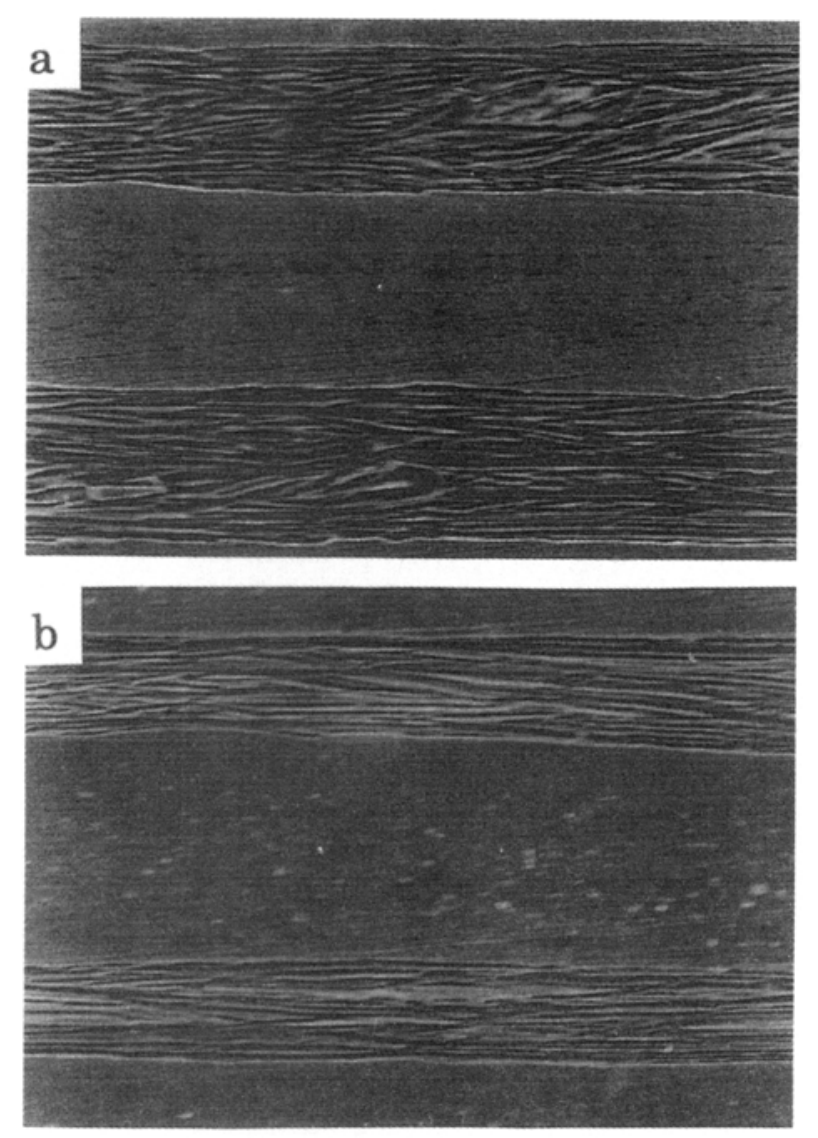

$10 \mu \mathrm{m}$

Figure 6. SEM micrographs observed on the longitudinal cross section of the $\mathrm{Bi}-2212 / \mathrm{Ag}$ multilayer tape processed without (a) and with (b) PAIR process. melting and subsequent slow cooling. We have fabricated $100 \mathrm{~m}$ long tapes with excellent $J_{c}$ properties and uniformity. After the heat treatment, the tape was coated

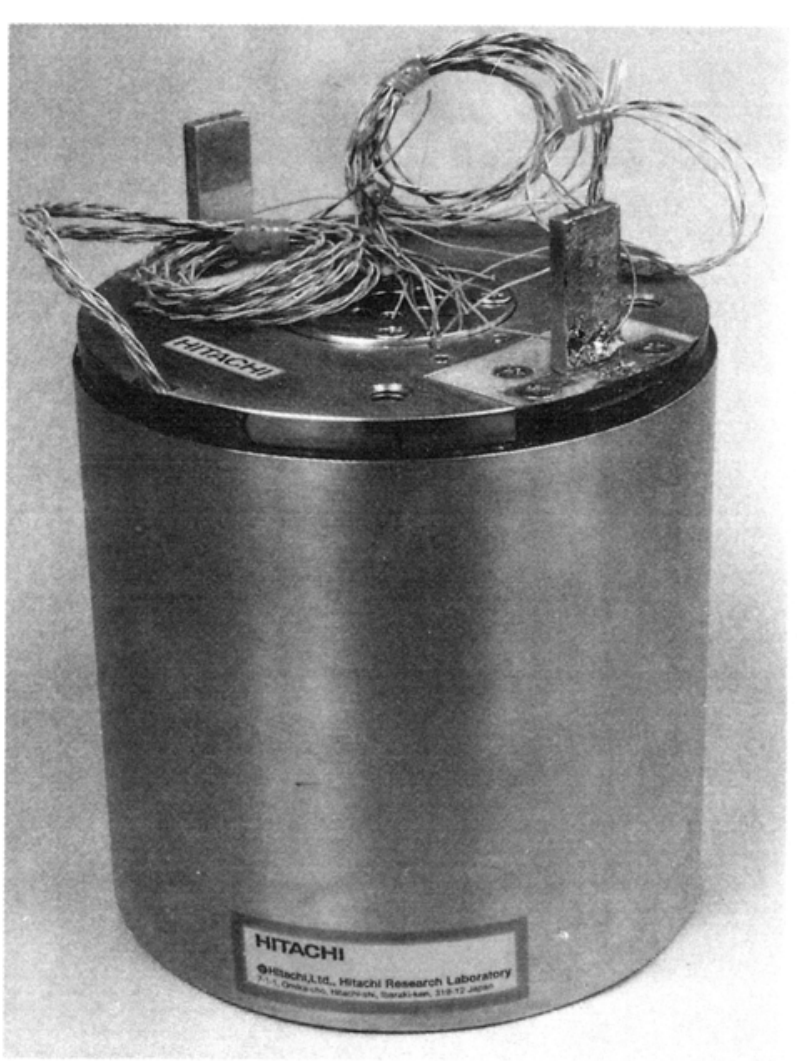

Figure 7. Bi-2212 test magnet designed as an insert magnet of the $\mathrm{Nb}-\mathrm{Ti} / \mathrm{Nb}_{3} \mathrm{Sn}$ superconducting magnet.

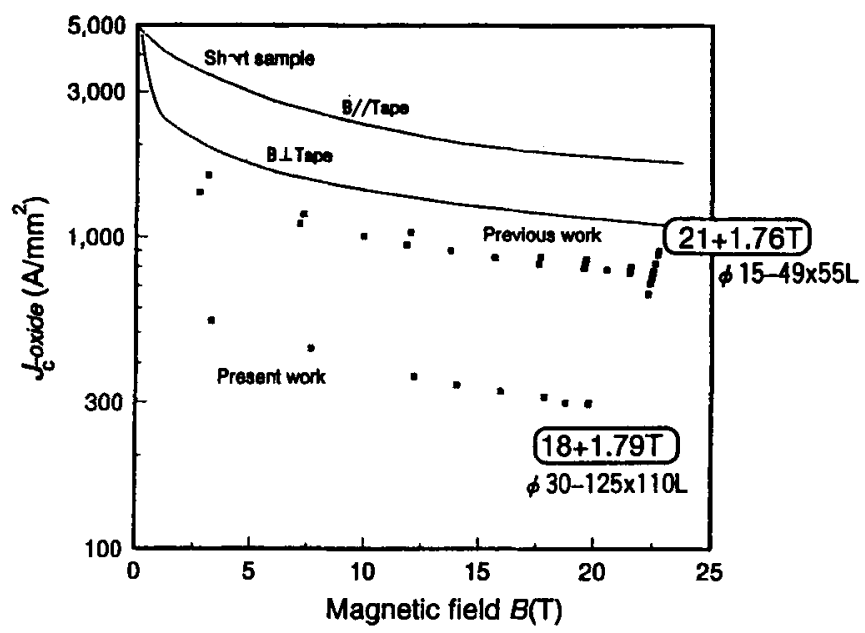

Figure 8. $J_{c}$ for the oxide core of the $\mathrm{Bi}-2212$ test magnet shown in figure 7 defined by the $10^{-13} \mathrm{ohm}-\mathrm{m}$ criterion as a function of the centre magnetic field (=applied field $(\mathrm{Nb}-$ $\left.\mathrm{Ti} / \mathrm{Nb}_{3} \mathrm{Sn}\right)+$ self filed $(\mathrm{Bi}-2212)$ ). The previous result (Okada et al 1996) for smaller coil is also shown for comparison. 
with polymide for insulation, and then wound around a $\mathrm{Cu}$ tube to make a double pancake coil. Voltage terminals were soldered on the outermost turn of the coil and on the Ag current leads. The coil was encased in a stainless steel frame and was impregnated with epoxy resin. The details of the tape and magnet fabrication process have been described elsewhere (Hasegawa et al 1997). The magnet has a clear bore of $60 \mathrm{~mm}$ diameter, outer diameter of $128 \mathrm{~mm}$ and $9.3 \mathrm{~mm}$ in height and was installed in a GM cryocooler system as shown in figure 9 to be tested at various temperatures. For comparison, conventional slow cooling heat treatment was also carried out using a box furnace for short tapes cut from the long tape.

We measured the voltage of the magnet at several temperatures as a function of time with various constant applied current. There was a critical current above which the voltage and temperature continue to go up with time, finally resulting in a thermal runaway of the magnet. Below this critical current, the voltage initially goes up slightly due to the heat generation at the current leads, however, the voltage saturates and becomes constant in a few minutes. We measured the voltage and temperature for $24 \mathrm{~h}$, and no changes were observed. Figure 10 shows the plot of this critical current as a function of operation temperature. At higher temperature region, the voltage increases and, hence, the temperature rise of the magnet

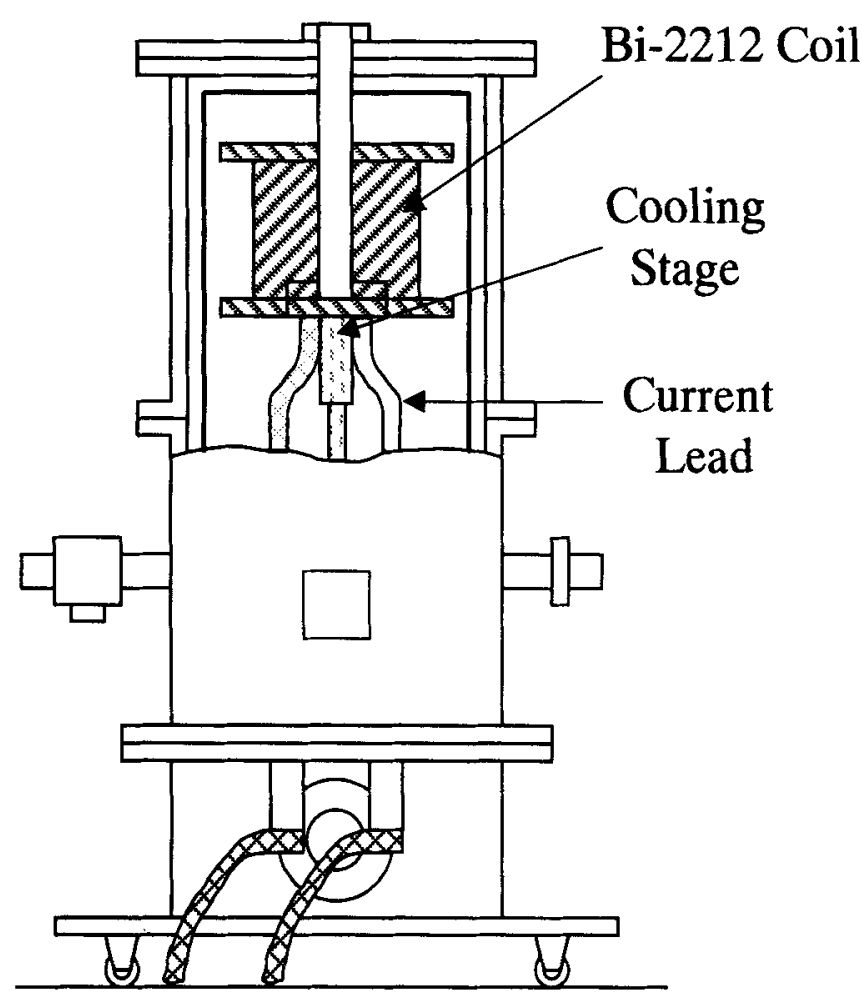

Figure 9. Test system of Bi-2212 coil under cryocooler operation. were slow due to the larger heat capacity of the magnet, and thermal runaway was observed several hours after the current was applied. Up to about $30 \mathrm{~K}$, the stable operating current density was equal or slightly lower than $J_{c}$ values. Above $30 \mathrm{~K}$, however, stable operating current density was higher than $J_{\mathrm{c}^{\prime}}$. The stable operating current density extrapolated to $4.2 \mathrm{~K}$ was lower than that obtained in liquid helium. This indicates that the heat transfer from the coil to cooling stage was smaller than that from the coil to liquid helium. At higher temperature region, heat generation in the magnet, $I_{\mathrm{c}} \times \mathrm{V}$, was small due to the low $J_{c}$ values which led to a stable operating current density higher than $J_{\mathrm{c}}$.

The highest stable operating current density of the coil at $20 \mathrm{~K}$ was $4.6 \times 10^{4} \mathrm{~A} / \mathrm{cm}^{2} \quad(I=95 \mathrm{~A})$ which is high enough for practical applications. At this current, the generated magnetic field was $0.78 \mathrm{~T}$. Calculation indicates that a magnet consisting of twelve double pancake coils with the same dimension generates about $3 \mathrm{~T}$ which is high enough for practical applications.

\section{Conclusions}

In this paper, we have reported our recent progresses in the development of $\mathrm{Bi}_{2} \mathrm{Sr}_{2} \mathrm{Ca}_{1} \mathrm{Cu}_{2} \mathrm{O}_{2} / \mathrm{Ag}$ tape conductors for the applications of magnetic field generation in liquid helium or at below $20 \mathrm{~K}$ by using a refrigerator. We

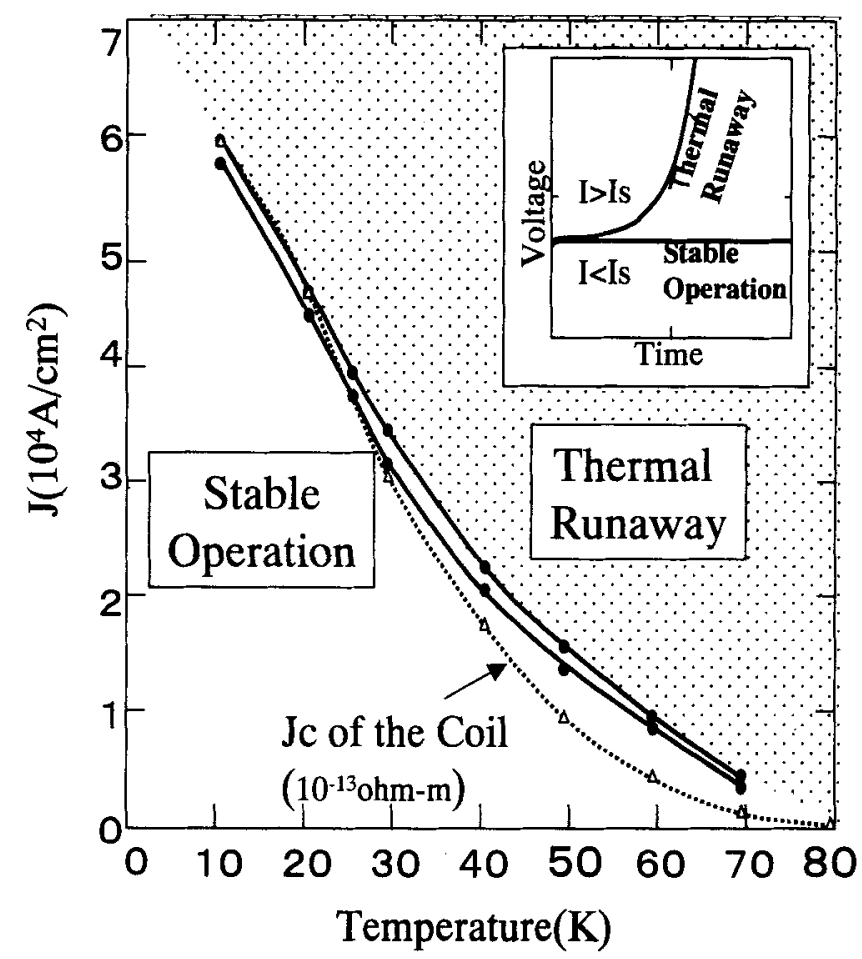

Figure 10. Plot of the current density $I_{\mathrm{S}}$ which is the broader of the stable operation and thermal runaway. The $J_{c}$ of the coil $\left(J_{c-c o i l}\right)$ defined by the $10^{-13} \mathrm{ohm}-\mathrm{m}$ criterion is also plotted for comparison. 
have carried out an extensive work to optimize the processing parameters, investigating the relationship between the microstructure and transport $J_{c^{\circ}}$. We have found that the partial melting in oxygen atmosphere is effective to have large transport with good reproducibility. The pre-annealing and intermediate rolling (PAIR) has been successfully applied to the multilayer conductors to improve the grain alignment and transport $J_{c}$. The $J_{\mathrm{c}}$ of $5 \times 10^{5} \mathrm{~A} / \mathrm{cm}^{2}$ at $4.2 \mathrm{~K}$ and $10 \mathrm{~T}$ has been achieved, which is the highest value reported so far.

Two magnets fabricated by using different types of $\mathrm{Bi}-2212 / \mathrm{Ag}$ conductors were tested. One is a magnet designed as an insert magnet for a $18 \mathrm{~T}$-class large bore $\mathrm{Nb}-\mathrm{Ti} / \mathrm{Nb}_{3} \mathrm{Sn}$ superconducting magnet. The conductor of this magnet was multifilamentary tape processed by powder-in-tube method. The magnet consists of ten double-pancake coils, and was tested in liquid helium in bias fields up to $18 \mathrm{~T}$. The $I_{\mathrm{c}}$ was $98 \mathrm{~A}$ in the backupfield of $18 \mathrm{~T}$, which corresponds to the $J_{\mathrm{c} \text {-nide }}$ of about $3 \times 10^{4} \mathrm{~A} / \mathrm{cm}^{2}$ and the $J_{\text {c-coil }}$ of $3.6 \times 10^{3} \mathrm{~A} / \mathrm{cm}^{2}$. At this current, the self-field of the insert magnet was $1.79 \mathrm{~T}$. A large pancake coil was fabricated with multilayer conductor and tested under the operation of cryocooler system. Below about $30 \mathrm{~K}$, the highest operating current densities for which the magnet was stably operated with GM cryocooler were almost equal to $J_{\text {c-coil }}$ values defined by $10^{-13} \mathrm{ohm}-\mathrm{m}$. At $20 \mathrm{~K}$, maximum stable operating current density was $4.6 \times 10^{4} \mathrm{~A} / \mathrm{cm}^{2}$ which was about
$70 \%$ of those at $4.2 \mathrm{~K}$, suggesting that a few Tesla will be easily attained by cryocooler operation by stacking many pancakes of $\mathrm{Bi}-2212$ conductors.

\section{References}

Balachandran U, Iyer A N, Halder P, Hoehn J G, Motowidlo L R and Galinski G 1994 Appl. Supercond. 2251

Fujii H, Kumakura H and Togano K 1997 J. Jap. Inst. Metals, 61856

Hasegawa T, Hikichi Y, Koizumi T, Imai A, Kumakura H, Kitaguchi H and Togano K 1997 IEEE Trans. Appl. Supercond. (in press)

Kase J, Morimoto T, Togano K, Kumakura H, Dietdrich D R and Maeda 1991 IEEE Trans. Magn. 241254

Kumakura H, Kitaguchi H, Togano K and Sugiyama N 1996 J. Appl. Phys. 805162

Miao $\mathrm{H}$, Kitaguchi $\mathrm{H}$, Kumakura $\mathrm{H}$, Togano $\mathrm{K}$ and Hasegawa T 1998a Physica C301 116

Miao H, Kitaguchi H, Kumakura H, Togano K, Hasegawa T and Koizumi T 1998b Physica C303 81

Okada M, Tanaka K, Sato J, Awaji S and Watanabe K 1995 Jpn J. Appl. Phys. 344770

Okada M et al 1996 Jpn J. Appl. Phys. 35 L623

Shibutani K, Hase T, Egi T, Hayashi S, Ogawa R and Kawate Y 1994 Appl. Supercond. 2237

Tenbrink J and Krauth H 1994 Adv. Cryogenic Eng. 40305

Tomita N et al 1994 Appl. Phys. Lett. 65898

Tomita N et al 1995 IEEE Trans. Appl. Supercond. 5520 